\title{
Reduced Lung Function at Preschool Age in Survivors of Very Low Birth Weight Preterm Infants
}

\author{
Hung-Yang Chang ${ }^{1,2}$, Jui-Hsing Chang ${ }^{1,2}$, Hsin Chi ${ }^{1,2}$, Chyong-Hsin Hsu ${ }^{1}$, Chia-Ying Lin ${ }^{1}$, \\ Wai-Tim Jim ${ }^{1}$ and Chun-Chih Peng ${ }^{1,2 *}$ \\ ${ }^{1}$ Department of Pediatrics, MacKay Children's Hospital, Taipei, Taiwan, ${ }^{2}$ Department of Medicine, MacKay Medical College, \\ New Taipei City, Taiwan
}

Background: Survivors of preterm birth are at risk of long-term respiratory consequences. The objective of this prospective study was to assess pulmonary function at preschool age of former very low birth weight (VLBW) preterm children.

Methods: Lung function of children born preterm and term controls aged 5-6 years were assessed by spirometry. The results were converted to z-scores. A questionnaire regarding respiratory symptoms was completed. Associations to gestational age $(\mathrm{GA})$, birth weight $(\mathrm{BW})$, bronchopulmonary dysplasia (BPD), and perinatal factors were assessed.

OPEN ACCESS

Edited by:

Arjan Te Pas,

Leiden University, Netherlands

Reviewed by:

Kazumichi Fujioka,

Kobe University, Japan

Andreas W. Flemmer,

Ludwig Maximilian University of

Munich, Germany

*Correspondence:

Chun-Chih Peng

pengcc4566@gmail.com

Specialty section:

This article was submitted to

Neonatology,

a section of the journal

Frontiers in Pediatrics

Received: 29 June 2020

Accepted: 24 August 2020 Published: 22 September 2020

Citation:

Chang $\mathrm{H}-\mathrm{Y}$, Chang $\mathrm{J}-\mathrm{H}$, Chi $\mathrm{H}$, Hsu C-H, Lin C-Y, Jim W-T and Peng C-C (2020) Reduced Lung Function at Preschool Age in Survivors of Very Low Birth Weight Preterm Infants. Front. Pediatr. 8:577673. doi: 10.3389/fped.2020.577673
Results: In total, 85 VLBW preterm children and 29 term controls were studied. Of the preterm children, the mean GA was $28.6 \pm 2.6$ weeks and the mean BW was $1,047 \pm 273 \mathrm{gm}$. Preterm children had significantly lower z-scores of forced expiratory volume in $1 \mathrm{~s}\left(\mathrm{FEV}_{1}\right), \mathrm{FEV}_{1}$ /forced vital capacity (FVC) ratio, and forced expiratory flow rate between $25-75 \%$ of $\mathrm{FVC}\left(\mathrm{FEF}_{25-75}\right)$, compared with term controls $(-0.73$ vs. $0.04, p=0.002 ;-0.22$ vs. $0.39, p=0.003 ;-0.93$ vs. $0.0, p<0.001$; respectively). Further segregation of the preterm group revealed significantly impaired $\mathrm{FEV}_{1}, \mathrm{FEF}_{25-75}$ in children at earlier gestation ( $\leq 28$ weeks, $n=45)$, lighter at birth $(\leq 1,000 \mathrm{~g}, n=38)$, or with BPD $(n=55)$ compared with term controls $(p<0.05)$. There were significant negative relationships between the severity of BPD with $\mathrm{FEV}_{1}, \mathrm{FVC}$, and $\mathrm{FEF}_{25-75}$ ( $p$ $<0.05$ ). However, no correlation between lung function measurements and respiratory symptoms was found.

Conclusions: VLBW preterm infants have reduced lung function at preschool age, especially among those with younger GA, lower BW, and BPD. Additional long-term follow-up of respiratory outcomes are needed for this vulnerable population.

Keywords: prematurity, lung function, bronchopulmonary dysplasia, spirometry, very low birth weight

\section{INTRODUCTION}

Improvements in perinatal and neonatal care have led to an increased survival for very low birth weight (VLBW; birth weight $<1,501 \mathrm{~g}$ ) preterm infants. However, morbidity among this vulnerable population remains high. The incidence of bronchopulmonary dysplasia (BPD) has shown no further decline over the past decade (1). BPD may cause irreversible damage to the lungs, which is related to long-term respiratory outcomes throughout life (1). Previous studies in the 
pre-surfactant era reported that airway obstruction and air trapping was common in preterm born children (1-4) particularly in those with a history of $\operatorname{BPD}(1,2,4,5)$. Despite widespread use of antenatal steroids, surfactant therapy, and less invasive ventilation strategies, more recent cohorts suggest that significant impairments in lung structure and lung function are still major concerns (6-10). Long-term follow-up studies in preterm survivors have demonstrated that lung function or respiratory health is impaired not only at preschool age, but may also persist into childhood, adolescence, and early adulthood (5, 11-14). Indeed, some evidence revealed a decrease in lung function in preterm infants, even though they had no serious respiratory diseases during the neonatal period $(15,16)$. This raises the concern that prematurity itself may have a significant effect on long-term respiratory morbidity.

Although most studies have shown a reduction in lung function in preterm infants, others have shown preserved lung function during childhood $(17,18)$. Whether the diagnosis of $\mathrm{BPD}$ is a risk factor for later pulmonary morbidity has also been questioned $(7,15,16,19)$. The controversy may be explained by differences in study population, the definition of BPD, and pulmonary function methods. However, studies on respiratory function in preschool children born preterm are limited (10, $20,21)$. It is not clear if any abnormalities in lung function are possible to detect earlier in life.

To better understand the importance of early pulmonary insults, we conducted this prospective, observational study to evaluate lung function in a cohort of VLBW preterm survivors at preschool age (5-6 years old). The aim of this study was to compare lung function in a group of former preterm-born children to that of a group of control children born at term with normal birth weight. We also examined the associations between gestational age (GA), birth weight (BW), and the presence of $\mathrm{BPD}$ in regards to lung function. Furthermore, we investigated whether the severity of BPD influences lung function.

\section{MATERIALS AND METHODS}

\section{Participants}

This prospective cohort study was performed at MacKay Children's Hospital, which is a level III perinatal center in Northern Taiwan. Preschool children aged 5-6 years, who were born at gestational age $<37$ weeks and with a birth weight $<1,500 \mathrm{~g}$, who were followed up at our institution's premature outpatient clinic, were invited to participate in this study. Term controls ( $\mathrm{GA} \geq 37$ weeks and $\mathrm{BW}>2,500 \mathrm{gm} \mathrm{g}$ ) at the same age were recruited from the outpatient clinic and wards from our hospital. Children with chromosomal abnormalities, major congenital heart or pulmonary diseases, neuromuscular diseases, significant neurodevelopmental disabilities, or inability to perform spirometry were excluded from the study. Asthma and atopy did not fall under the exclusion criteria. The study protocol was approved by the institutional review board of our institution (IRB number: 16MMHIS162e). Written informed consent was obtained from the parents or guardians of each participating child.
Data regarding the perinatal and neonatal periods for the preterm birth children were obtained from chart reviews. Small for gestational age (SGA) was defined as a birth weight below the 10th percentile according to a Taiwanese sex- and gestational agespecific reference for normal fetal growth. BPD was defined and its severity was classified according to the National Heart, Lung, and Blood Institute workshop criteria (22).

\section{Assessment of Lung Function}

All subjects underwent a standardized clinical examination by pediatricians. Height, weight, and body mass index were measured and expressed as z-scores, adjusted for sex and age according to Taiwanese children references. At the time of lung function measurement, all participants were in stable clinical condition, without any acute respiratory tract symptoms on the day of testing, or in the previous 2 weeks. Children were asked to withhold the use of short-acting bronchodilators for 1 day before testing.

Spirometry was performed by a single experienced technician, and data were analyzed by respiratory specialists who were all blinded to the clinical details of the participant. Spirometry was performed using a spirometer (Ultima PF with RTD; MGC Diagnostics, Saint Paul, MN, USA). Measurements were performed according to the American Thoracic Society and European Respiratory Society guidelines (23). During spirometry, attempts were made to achieve at least three technically acceptable sequences. The best maneuvers among those considered technically acceptable were recorded. Flowvolume curves were obtained in order to determine the following spirometric parameters: forced expiratory volume in one second $\left(\mathrm{FEV}_{1}\right)$, forced vital capacity (FVC), $\mathrm{FEV}_{1} / \mathrm{FVC}$ ratio, and forced expiratory flow between 25 and $75 \%$ of expired $\mathrm{FVC}\left(\mathrm{FEF}_{25-75}\right)$. Lung function data were expressed as z-scores after adjustment for height, sex, age, and race according to the Global Lung Function Initiative reference (24). Any z-scores of lung function measurements $<-1.96$ were considered abnormal.

\section{Respiratory Morbidity}

Parents completed a questionnaire regarding their child's respiratory morbidity and relevant family history. The questionnaire was based on the modified Chinese version of the International Study of Asthma and Allergies in Childhood (ISAAC) questionnaire (25). Factors such as maternal smoking in pregnancy, as well as current passive smoke and pet exposure were recorded. A family history of atopy was considered positive if there was an atopic disease (atopic dermatitis, allergic rhinitis, asthma) in a first-degree relative. The questionnaire also included questions on the presence of respiratory symptoms, history of wheezing, rehospitalization due to lower respiratory tract infections (bronchiolitis, pneumonia), presence of diagnosed atopic diseases, and allergies. Regular prophylactic asthma medication included inhaled corticosteroids, beta-2-agonists, or anti-leukotriene agents within the preceding 12 months.

\section{Statistical Analysis}

A sample size of 40 individuals was calculated to have enough power $(80 \%)$ to detect at least a 0.75 -point difference in the 
$\mathrm{FEV}_{1} \mathrm{Z}$-score mean value between preterm and term control groups. Categorical data were expressed as proportions and analyzed by the chi-square test or Fisher's exact test, as appropriate. The numerical data are presented as the mean \pm S.D. and analyzed by the Student's $t$-test for independent samples if normally distributed, or by the Mann-Whitney $U$ test if skewed. Differences in lung function variables between subgroups were assessed by one-way analysis of variance (ANOVA) with post-hoc comparisons. If the overall $P$-value from ANOVA was statistically significant, differences between subgroups were tested. The Jonckheere-Terpstra test was used to assess trends in lung function parameters across the four groups with varying BPD severity. The relationships between neonatal factors and lung function were initially assessed using Pearson's correlation test and univariate linear regressions. Neonatal factors with significant univariate correlation to function outcomes were included in the multiple linear regressions. Statistical procedures were performed with IBM SPSS version 25.0 for Windows (SPSS Inc., Chicago, IL, USA). For all analyses, a $P$-value $<0.05$ was considered statistically significant.

\section{RESULTS}

\section{Study Population Characteristics}

At preschool age, 153 former VLBW children who attended our follow-up program were invited to join this study. Of these, 89 (58.2\%) subjects consented to participate in the current study. After excluding individuals unable to perform spirometry reliably (4 subjects), 85 participants born preterm (preterm group) were enrolled in this study. The preterm group was born between April 2015 and March 2017 at a mean GA of $28.6 \pm 2.7$ weeks and with a mean BW of $1,039 \pm 247 \mathrm{~g}$. Demographic, perinatal, and neonatal characteristics for the VLBW survivors are presented in Table 1. The 85 children represented 25\% of the 345 VLBW survivors born during the same period at MacKay Children's Hospital. With the exception of a lower BW (1,039 vs. 1,117 g; $p=0.025$ ) and a marginally higher incidence of sepsis (24 vs. $14 \%, p=0.055)$ in the study subjects, there were no significant differences in perinatal characteristics and neonatal outcomes between the VLBW study cohort and the VLBW survivors who were not included in the study (Table 1). The comparison group comprised 29 term-born controls (control group) with a mean GA of $38.5 \pm 1.0$ weeks and a mean BW of 3,030 $\pm 322 \mathrm{~g}$. Except for GA and BW $(p<0.001)$, there were no significant differences in sex, Apgar scores, and delivery methods between the preterm and control groups.

At the time of the lung function test, the health characteristics of all participating children were summarized in Table 2. The term controls were slightly older than the preterm children because we recruited the control children after the pretermborn children had visited. Children in the preterm group were significantly shorter and lighter than term controls, but there was no difference in body mass index (BMI). Family history of atopy, passive smoke exposure, and respiratory morbidity were also similar between both groups (Table 2).

\section{Pulmonary Function Results Comparison of Lung Function in the Preterm Group and Term Controls}

After adjusting for age, sex, and height, z-scores of the lung function test of the term control and the preterm group are presented in Table 3. The preterm group had significantly lower spirometric measurements $\left(\mathrm{FEV}_{1}, p=0.002\right.$; $\mathrm{FEV}_{1} / \mathrm{FVC}, p=$ 0.003 ; and $\mathrm{FEF}_{25-75}, p<0.001$ ) than the term control children, which were further decreased in those with lower GA, lighter BW, and with a history of BPD. Pearson's correlation and linear regression analysis revealed a positive significant correlation between GA, BW, and all spirometry results. The proportion of lung function below the lower limit (defined as any of $\mathrm{FEV}_{1}$, $\mathrm{FVC}, \mathrm{FEV}_{1} / \mathrm{FVC}$, or $\mathrm{FEF}_{25-75} \leq-1.96 \mathrm{z}$-scores) was significantly higher in the preterm group than in the term controls (26 vs. $10 \%$, $p=0.042$ ). Sex, delivery mode, and SGA did not affect spirometry outcomes between preterm and term groups. The analyses also revealed no significant associations of respiratory morbidities, allergy history, and lung function data between the two groups.

\section{GA Subgroup and Lung Function (Table 3)}

Z-scores of $\mathrm{FEV}_{1}, \mathrm{FEV}_{1} / \mathrm{FVC}$, and $\mathrm{FEF}_{25-75}$ were significantly lower in children born $\leq 28$ weeks of gestation than in term controls $(P=0.003,0.004$, and $<0.001$, respectively), but not for FVC $(P=0.07)$. Children in the $\leq 28$ weeks subgroup also had significantly impaired $\mathrm{FEV}_{1} / \mathrm{FVC}$ and $\mathrm{FEF}_{25-75}$ compared to children in the 29-36 weeks subgroup $(P=0.008$ and $<0.001$, respectively). Except for $\mathrm{FEV}_{1}(p=0.04)$, there were no differences between the 29-36 weeks subgroup and term controls. The proportion of children with lung function below the lower limit of normal in the $\leq 28$ weeks subgroup (36\%) was significantly higher than in the 29-36 weeks subgroup (15\%) and term controls $(10 \%)(P=0.008$ and 0.028 , respectively).

\section{BW Subgroup and Lung Function (Table 3)}

All spirometry values were significantly lower in children with a $\mathrm{BW} \leq 1,000 \mathrm{gm}(\mathrm{ELBW})$ than in term controls $\left(\mathrm{FEV}_{1}, p<\right.$ 0.001 FVC, $p=0.002 ; \mathrm{FEV}_{1} / \mathrm{FVC}, p=0.01 ; \mathrm{FEF}_{25-75}, P<$ $0.001)$. Children in the ELBW subgroup also had significantly impaired $\mathrm{FEV}_{1}, \mathrm{FVC}$, and $\mathrm{FEF}_{25-75}$ than children in the 1,0011,500 g subgroup $(P=0.001,0.006$, and 0.014 , respectively). The proportion of lung function below the lower limit of normal in the $\leq 1,000$ g subgroup ( $42 \%$ ) was significantly higher than in the $1,001-1,500 \mathrm{~g}$ subgroup (13\%) and term controls $(10 \%)(P=$ 0.003 and 0.002 , respectively).

\section{BPD, Severity of BPD, and Lung Function (Table 3 and Figure 1)}

Among children in the preterm group, 55 (65\%) had BPD in the neonatal period. All spirometry values were significantly lower in preterm children with BPD than in term controls (Table 3, $\mathrm{FEV}_{1}$, $p<0.001$; FVC, $p=0.02$; $\mathrm{FEV}_{1} / \mathrm{FVC}, p=0.004 \mathrm{FEF}_{25-75}, P$ $<0.001)$. The preterm children in the BPD subgroup also had significantly lower FEV1 and $\mathrm{FEF}_{25-75}$ than the preterm no BPD subgroup (Table 3, $P=0.01,0.005$, respectively).

Lung function results according to the BPD severity classification are presented in Figure 1. Among the preterm 
TABLE 1 | Perinatal characteristics of very low birth weight preterm infants who were enrolled in this study.

\begin{tabular}{|c|c|c|c|}
\hline & $\begin{array}{l}\text { Enrolled group } \\
\qquad N=85\end{array}$ & $\begin{array}{l}\text { Not enrolled Group } \\
\qquad N=260\end{array}$ & $p$-value \\
\hline Antenatal steroids (\%) & 86 & 87 & 0.708 \\
\hline PROM > 18h (\%) & 30 & 26 & 0.519 \\
\hline Cesarean section (\%) & 68 & 75 & 0.206 \\
\hline $\mathrm{BW}, \mathrm{gm}(\text { mean } \pm S D)^{\star}$ & $1,039 \pm 247$ & $1,117 \pm 259$ & 0.025 \\
\hline Small for gestational age (\%) & 36 & 35 & 0.956 \\
\hline Male gender (\%) & 46 & 48 & 0.793 \\
\hline Apgar score at $5 \mathrm{~min}<7(\%)$ & 10 & 8 & 0.595 \\
\hline Surfactant administration (\%) & 40 & 35 & 0.366 \\
\hline Pneumothorax (\%) & 2 & 3 & 0.742 \\
\hline BPD (\%) & 73 & 64 & 0.128 \\
\hline Sepsis (\%) & 24 & 14 & 0.055 \\
\hline PDA need treatment (\%) & 38 & 38 & 0.998 \\
\hline NEC $\geq$ stage $2(\%)$ & 1 & 3 & 0.552 \\
\hline $\mathrm{ROP} \geq$ stage $3(\%)$ & 7 & 10 & 0.382 \\
\hline Severe IVH (\%) & 7 & 6 & 0.649 \\
\hline Cystic PVL (\%) & 4 & 7 & 0.152 \\
\hline
\end{tabular}

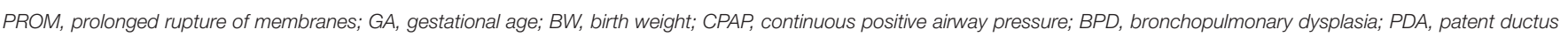
arteriosus; NEC, necrotizing enterocolitis; ROP, retinopathy of prematurity; IVH, intraventricular hemorrhage; PVL, periventricular leukomalacia.

Data are presented as mean (SD) or number (\%).

${ }^{*} p<0.05$.

group with $\mathrm{BPD}$, nine were classified as mild, 20 as moderate, and 26 as severe BPD. The most marked reductions were seen in children in the severe BPD subgroup, in whom all lung function results were significantly lower than in term controls (all had $p<0.001$ ). A significant difference in lung function, which was lower in children with severe BPD compared to the moderate, mild, and no BPD subgroup was also seen for $\mathrm{FEV}_{1}(P<0.001,0.005$, and $<0.001$, respectively $)$, FVC $\left(p=0.003,0.017\right.$, and $<0.001$, respectively), $\mathrm{FEF}_{25-75}(p=$ $0.014,0.035$, and $<0.001$, respectively). Preterm children in the moderate BPD subgroup also had significantly lower $\mathrm{FEV}_{1}$ and $\mathrm{FEF}_{25-75}$ than children in term controls $(P=0.038$ and $P=0.021$, respectively). There were no differences in any lung function variables between the moderate $\mathrm{BPD}$, mild $\mathrm{BPD}$, and no BPD subgroups. In the preterm group, there was a significant trend toward a decreased value of $\mathrm{FEV}_{1}$, FVC, and $\mathrm{FEF}_{25-75}$ as the grade of BPD severity increased (Figure 1, Jonckheere-Terpstra trend test $p<0.001,0.003$, and $<0.001$, respectively). The proportion of lung function below the lower limit of normal in the severe BPD subgroup (50\%) was significantly higher than that in the moderate BPD $(20 \%)$, no BPD (10\%), and term controls $(10 \%)(P=0.03,0.001$, and 0.001 , respectively).

\section{Perinatal Factors and Lung Function in the Preterm Group}

Associations between lung function and the factors summarized in Table 1 were investigated. Univariate analysis showed lower GA and lighter BW, longer duration of mechanical ventilation and oxygen treatment, and a history of BPD were significantly associated with lower $\mathrm{FEV}_{1}, \mathrm{FVC}$, and $\mathrm{FEF}_{25-75} \mathrm{z}$-scores. However, in multivariate regression analysis using $\mathrm{BW}$, the duration of mechanical ventilation, and BPD as covariates, BW was an independent variable that only moderately correlated with $\mathrm{FEV}_{1}, \mathrm{FVC}$, and $\mathrm{FEF}_{25-75}(r=0.49, P=0.003 ; r=0.39, P=0.04$; and $r=0.49, P=0.008$, respectively).

\section{DISCUSSION}

This study provides the most up-to-date lung function results in a cohort of VLBW preterm children, born in the era of the use of surfactant and non-invasive respiratory support strategies. Nearly $90 \%$ of our preterm children had received antenatal corticosteroids. Despite widespread use of these modern treatments, the results of the present study show that lung function was significantly impaired 
TABLE 2 | Characteristics of the study population at the time of the lung function test.

\begin{tabular}{|c|c|c|c|}
\hline & $\begin{array}{l}\text { Preterm group } \\
\qquad N=85\end{array}$ & $\begin{array}{c}\text { Term Control group } \\
\qquad N=29\end{array}$ & $p$-value \\
\hline Age $\left(\right.$ year) $(\text { mean } \pm S D)^{\star}$ & $5.6 \pm 0.6$ & $5.9 \pm 0.5$ & 0.002 \\
\hline Height z-score $(\text { mean } \pm S D)^{\star}$ & $-0.81 \pm 0.92$ & $-0.12 \pm 0.94$ & 0.001 \\
\hline Weight z-score $(\text { mean } \pm S D)^{\star}$ & $-0.86 \pm 1.02$ & $-0.21 \pm 1.17$ & 0.005 \\
\hline Passive smoke exposure (\%) & 38 & 34 & 0.763 \\
\hline Pets in the home (\%) & 14 & 21 & 0.406 \\
\hline \multicolumn{4}{|l|}{ Respiratory Morbidity } \\
\hline Wheeze ever (\%) & 65 & 59 & 0.780 \\
\hline Wheeze in last $12 \mathrm{~m}(\%)$ & 53 & 52 & 0.798 \\
\hline Respiratory hospitalization $\geq 3(\%)$ & 8 & 9 & 0.763 \\
\hline
\end{tabular}

$B M I$, body mass index.

${ }^{*} p<0.05$.

TABLE 3 | Lung function results of the preterm group, stratified by GA, BW, and BPD, compared to term controls (expressed as z-scores).

\begin{tabular}{|c|c|c|c|c|}
\hline & FEV $_{1}$ & FVC & $\mathrm{FEV}_{1} / \mathrm{FVC}$ & FEF $_{25-75}$ \\
\hline \multicolumn{5}{|c|}{ Term Control Group $(N=29)$} \\
\hline & $0.04 \pm 1.18$ & $-0.12 \pm 1.14$ & $0.39 \pm 0.85$ & $0.00 \pm 1.23$ \\
\hline \multicolumn{5}{|l|}{ Preterm Group $(N=85)$} \\
\hline & $-0.73 \pm 1.12^{\star \star}$ & $-0.60 \pm 1.20$ & $-0.22 \pm 0.16^{\star \star}$ & $-0.93 \pm 1.14^{\star \star \star}$ \\
\hline \multicolumn{5}{|l|}{ Preterm, GA Subgroup } \\
\hline \multicolumn{5}{|l|}{ Preterm, BW Subgroup } \\
\hline$\leq 1,000 \mathrm{~g}(N=38)$ & $-1.17 \pm 0.98^{t+x+\alpha \alpha}$ & $-1.00 \pm 1.08^{* *, \alpha \alpha}$ & $-0.30 \pm 1.28^{\star}$ & $-1.26 \pm 1.19^{* * *, \alpha}$ \\
\hline $1,001-1,500 \mathrm{~g}(\mathrm{~N}=47)$ & $-0.38 \pm 1.12$ & $-0.29 \pm 1.22$ & $-0.17 \pm 1.06^{\star}$ & $-0.66 \pm 1.04^{*}$ \\
\hline \multicolumn{5}{|l|}{ Preterm, BPD Subgroup } \\
\hline $\mathrm{BPD}(N=55)$ & $-0.96 \pm 1.08^{* * *, \mu}$ & $-0.78 \pm 1.23^{*}$ & $-0.32 \pm 1.29^{\star \star}$ & $-1.18 \pm 1.14^{*+* x \mu \mu}$ \\
\hline
\end{tabular}

$G A$, gestational age; BW, birth weight; $B P D$, bronchopulmonary dysplasia; $F E V_{1}$, forced expiratory volume in $1 \mathrm{~s} ; F V C$, forced vital capacity; $F E F_{25-75}$, forced expiratory flow between 25 and $75 \%$ of expired FVC.

Data were adjusted for age, sex, and height and are expressed as mean $\pm S D$.

${ }^{\star} p<0.05$ vs. controls, ${ }^{* *} p<0.01$ vs. controls, ${ }^{* * *} p<0.001$ vs. controls.

$\# p<0.05$ vs. GA 29-36 wk, \#\# $p 0.01$ vs. GA 29-36 wk.

${ }^{\alpha} p<0.05$ vs. $B W>1,000 \mathrm{~g},{ }^{\alpha \alpha} p<0.01$ vs. $B W>1,000 \mathrm{~g}$.

$\mu_{p}<0.05$ vs. no BPD, ${ }^{\mu \mu} p<0.01$ vs. no BPD.

at preschool age in former VLBW preterm infants when compared with term controls. Although the mean values of all spirometry results in both groups were in the normal range, the preterm children still had a significantly high proportion of abnormal lung function. Furthermore, preterm children with earlier GA, lower BW, and a diagnosis of BPD in early life was associated with a marked reduction in spirometry.
Our findings are in accordance with previous reports from most contemporary cohorts (6-10). Children born preterm are at high risk for large airway obstructions, as assessed by $\operatorname{FEV}_{1}(8,19$, 26). Reduction in small airways patency, as assessed by $\mathrm{FEF}_{25-75}$, also continues to be reported throughout various school ages $(6,19,26,27)$. The persistence of airway obstruction, airflow limitation, and air trapping in these children is multifactorial in nature, potentially reflecting the impact of preterm birth per 


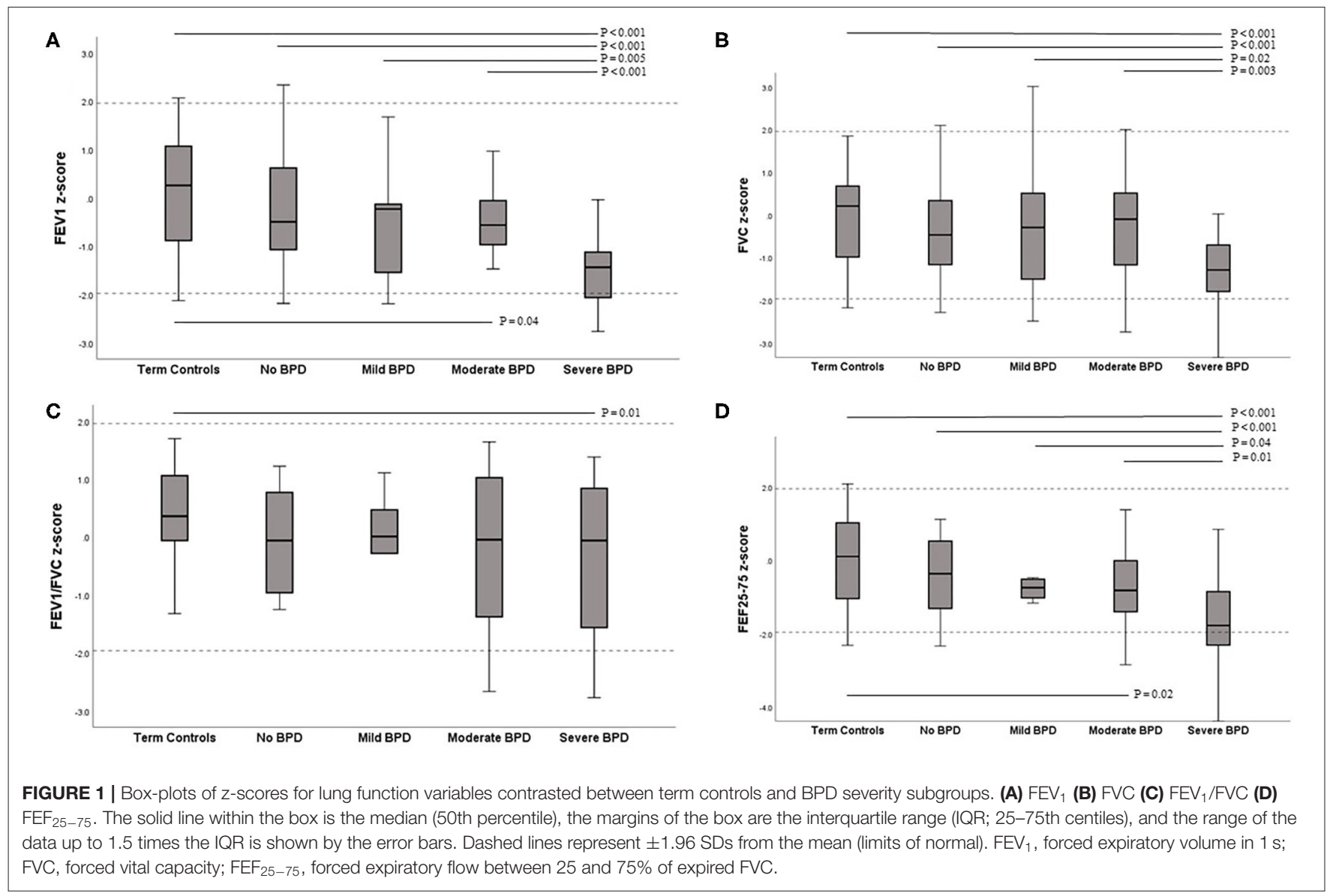

se. The vulnerability of the immature lung is susceptible to early life adverse exposures, such as volutrauma, atelectrauma, barotrauma, biotrauma, and oxygen toxicity (1). Preterm itself, together with these injuries, might result in impaired lung growth, with smaller airways and decreased lung volume (22). In our study, the difference in the mean values of the $\mathrm{z}$ scores of $\mathrm{FEV}_{1}, \mathrm{FEV}_{1} / \mathrm{FVC}$, and $\mathrm{FEF}_{25}-75$ between preterm and term controls was $-0.77,-0.61$, and -0.93 , respectively. These differences were even greater in the GA $\leq 28$ weeks subgroup than in the controls in the current study. A recent meta-analysis also confirmed that younger gestational age had a lower $\mathrm{FEV}_{1}$, $\mathrm{FEV}_{1} / \mathrm{FVC}$, and $\mathrm{FEF}_{75}$ in childhood $(1,28)$. Together with our data, these studies indicate that the degree of preterm birth has an effect on later lung function.

In agreement with previous studies, low BW is associated with decreased lung function in preterm children $(3,7,11,27$, 29). A previous meta-analysis and studies from longitudinal birth cohorts reported independent effects and strong positive associations of BW with $\mathrm{FEV}_{1}$ and $\mathrm{FEF}_{25-75}$ (30). Low BW with relatively small airways could result in a reduction in expiratory flow, reflected by lower lung function values. However, low BW includes both immature infants with appropriate growth for gestation, and intrauterine growth restriction (IUGR), who may be physiologically mature at birth. The mechanisms that lead to lung function deficits are different in these two conditions.
However, we did not find the association between IUGR and lower lung function in the present study.

A recent meta-analysis by Ronkainen et al. confirmed that school-aged children born preterm with BPD have impaired pulmonary function measurements (8). Simpson et al. showed a reduction of $-1.06 \mathrm{z}$-score $\mathrm{FEV}_{1}$ for the $\mathrm{BPD}$ group, which is comparable to our study (29). In contrast, preterm children without BPD have similar lung function results compared to term controls. Long-term follow-up of BPD survivors has also demonstrated the persistence of airway obstructions and air trapping into childhood, adolescence, and adulthood $(1,4,11$, 26, 31-33). However, conflicts exist regarding BPD severity classification and long-term lung function $(8,10,34)$. Brostrom et al. reported that the impairment of lung function was most pronounced in severe BPD (15). Hirata et al. also showed that the classification of BPD severity was useful for predicting the impairment of long-term lung function (35). Consistent with these reports, we found that the severity of BPD had a significant negative association with $\mathrm{FEV}_{1}, \mathrm{FVC}$, and $\mathrm{FEF}_{25-75}$. However, flow characteristics in mild BPD were not significantly different from those of preterm children without BPD and term controls. It might be speculated that mild BPD in preterm infants may not result in long-term respiratory consequences. However, these results should be interpreted cautiously, given the small number of mild cases in the present study. 
The duration of oxygen supplementation and mechanical ventilation have been associated with diminished lung function in many studies $(7,9,29,32,36)$. However, they might be more closely related to the degree of prematurity itself. Many other perinatal factors have been identified as important factors predicting adverse lung function in childhood. These include but are not limited to antenatal steroids, maternal nutrition, maternal pregnancy disorders (hypertensive disorders, gestational diabetes, chorioamnionitis), parental smoking, socioeconomic status, IUGR, sex, and neonatal caffeine administration $(12,37,38)$. However, we did not find an association between these factors and lung function. Neither family atopic history nor exposure to pets was associated with any of the lung function measurements in the present study.

Preterm birth or low birth weight is associated with an increased risk of respiratory morbidities, especially in those with $\operatorname{BPD}(19,28,39)$. Asthma or recurrent wheezing, use of asthma medications, and hospitalization for respiratory infections are more prevalent later in life in those born preterm than term controls (9, 21, 40). Preterm children with these respiratory morbidities are likely to negatively influence lifetime lung function (26). However, we found no significant difference in respiratory morbidities between the preterm group and term controls. Furthermore, no correlation was identified between pulmonary function test results and the presence of respiratory morbidities in the present study. It is still unclear if the deficits in pulmonary function are translated into increased respiratory symptoms. Therefore, further studies are needed to disentangle the direction of causality.

This study has several limitations. The main limitation is the large loss to follow-up rate in our cohort of survivors. Selection bias may already exist due to sepsis being marginally higher in the enrolled patients since sepsis has been recognized as a risk factor for BPD $(41,42)$. Except for BW and sepsis, given that perinatal factors were similar between the VLBW preterm children who were included in the present study and those who were not, we are confident that the results reported represent the total cohort of survivors. Second, the questionnaire reported by parents may not be accurate, and they may overestimate the incidence of wheeze symptoms and asthma. Third, the lack of a true normal control population of healthy children is another concern. Parents may have been more motivated to participate in this study than others if their children had respiratory symptoms. Although the term controls were significantly older than preterm group, the z-scores calculations of each lung function parameter were already adjusted for age. Otherwise, the mean spirometry data in our control group exhibited approximately 0.0 z-scores, indicating that they can be used as a reference group. However, older participants in the term controls also raised the concern that they may perform better at spirometry than preterm children. Although it is not easy to perform spirometry in this age, our technician trained these children well and conducted the test according to the guidelines. Furthermore, we only performed baseline lung function tests; after exercise or bronchodilator administration tests were not assessed in this study. Further studies with adequate power are also needed to identify which perinatal factors are related to long-term adverse respiratory and lung function outcomes.

In conclusion, preterm-born children at preschool age had significantly reduced lung function compared with the term controls. Stratified analyses showed the worst results in preterm children with younger GA, lower BW, and with BPD. The deficits were particularly evident in pulmonary flow measurements, reflective of increased airway obstructions. The severity of $\mathrm{BPD}$ can be a predictor of lung function impairment, as severe BPD had the worst lung function outcomes. However, preterm children without BPD or with mild BPD had similar lung functions to term controls. No correlation between lung function and respiratory symptoms in this study needs further investigation. Our study suggests that adverse effects of preterm birth on lung function can be detected in early childhood. It has been proposed that preterm birth may predispose individuals to chronic obstructive pulmonary disease. With increasing survival of preterm births, efforts should be made to identify subgroups at higher risk of impaired lung function in later life. Longterm follow-up of lung function in VLBW preterm infants is warranted.

\section{DATA AVAILABILITY STATEMENT}

The original contributions presented in the study are included in the article/supplementary material, further inquiries can be directed to the corresponding author/s.

\section{ETHICS STATEMENT}

The studies involving human participants were reviewed and approved by Institutional Review Board of MacKay Memorial Hospital (IRB number: 16MMHIS162e). Written informed consent to participate in this study was provided by the participants' legal guardian/next of kin.

\section{AUTHOR CONTRIBUTIONS}

$\mathrm{H}-\mathrm{YC}, \mathrm{HC}$, and $\mathrm{C}-\mathrm{CP}$ designed the project of this study. J-HC, C-HH, and C-YL performed participant recruitment. $\mathrm{H}-\mathrm{YC}$ and $\mathrm{W}-\mathrm{TJ}$ performed data collection and statistics. $\mathrm{H}-\mathrm{YC}, \mathrm{J}-\mathrm{HC}$, and $\mathrm{C}-\mathrm{CP}$ prepared the draft of the manuscript. All authors approved the final manuscript as submitted and agree to be accountable for all aspects of the work.

\section{ACKNOWLEDGMENTS}

The authors are grateful to Mrs. Chiayu Lin for patient recruitment and data collection, and Mrs. Cheng-Yu Chang for her valuable assistance during the development of this research work. We would also like to thank the children and the families who participated in this study. 


\section{REFERENCES}

1. Baraldi E, Filippone M. Chronic lung disease after premature birth. $N$ Engl J Med. (2007) 357:1946-55. doi: 10.1056/NEJMra067279

2. Northway WH, Moss RB, Carlisle KB, Parker BR, Popp RL, Pitlick PT, et al. Late pulmonary sequelae of bronchopulmonary dysplasia. $N$ Engl J Med. (1990) 323:1793-9. doi: 10.1056/NEJM199012273232603

3. Kennedy JD, Edward LJ, Bates DJ, Martin AJ, Dip SN, Haslam RR, et al. Effects of birthweight and oxygen supplementation on lung function in late childhood in children of very low birth weight. Pediatr Pulmonol. (2000) 30:32-40. doi: 10.1002/1099-0496(200007)30:1<32::aid-ppul6>3.0.co;2-9

4. Doyle LW, Faber B, Callanan C, Freezer N, Ford GW, Davis NM. Bronchopulmonary dysplasia in very low birth weight subjects and lung function in late adolescence. Pediatrics. (2006) 118:108-13. doi: 10.1542/peds.2005-2522

5. Vollsaeter M, Roksund OD, Eide GE, Markestad T, Halvorsen T. Lung function after preterm birth: development from mid-childhood to adulthood. Thorax. (2013) 68:767-76. doi: 10.1136/thoraxinl-2012-202980

6. Korhonen P, Laitinen J, Hyodynmaa E, Tammela O. Respiratory outcome in school-aged, very-low-birth-weight children in the surfactant era. Acta Paediatr. (2004) 93:316-21. doi: 10.1080/08035250410023593

7. Cazzato S, Ridolfi L, Bernardi F, Faldella G, Bertelli L. Lung function outcome at school age in very low birth weight children. Pediatr Pulmonol 48. (2013) 830-7. doi: $10.1002 /$ ppul.22676

8. Ronkainen E, Dunder T, Peltoniemi O, Kaukola T, Marttila R, Hallman M. New BPD predicts lung function at school age: follow-up study and meta-analysis. Pediatr Pulmonol. (2015) 50:1090-8. doi: 10.1002/ppul.23153

9. Verheggen M, Wilson AC, Pillow JJ, Stick SM, Hall GL. Respiratory function and symptoms in young preterm children in the contemporary era. Pediatr Pulmonol. (2016) 51:1347-55. doi: 10.1002/ppul.23487

10. Thunqvist P, Tufvesson E, Bjermer L, Winberg A, Fellman V, Domellof $\mathrm{M}$, et al. Lung function after extremely preterm birth-A population-based cohort study (EXPRESS). Pediatr Pulmonol. (2018) 53:64-72. doi: 10.1002/ppul.23919

11. Gibson AM, Reddington C, McBride L, Callanan C, Robertson C, Doyle LW. Lung function in adult survivors of very low birth weight, with and without bronchopulmonary dysplasia. Pediatr Pulmonol. (2015) 50:98794. doi: 10.1002/ppul.23093

12. Nasanen-Gilmore P, Sipola-Leppanen M, Tikanmaki M, Matinolli $\mathrm{HM}$, Eriksson JG, Jarvelin MR, et al. Lung function in adults born preterm. PLoS ONE. (2018) 13:e0205979. doi: 10.1371/journal.pone. 0205979

13. Doyle LW, Andersson S, Bush A, Cheong JLY, Clemm H, Evensen KAI, et al. Adults born Preterm International, Expiratory airflow in late adolescence and early adulthood in individuals born very preterm or with very low birthweight compared with controls born at term or with normal birthweight: a meta-analysis of individual participant data. Lancet Respir Med. (2019) 7:677-86. doi: 10.1016/S2213-2600(18)30530-7

14. Doyle LW, Adams AM, Robertson C, Ranganathan S, Davis NM, Lee KJ, et al. Infant Collaborative Study, Increasing airway obstruction from 8 to 18 years in extremely preterm/low-birthweight survivors born in the surfactant era. Thorax. (2017) 72:712-9. doi: 10.1136/thoraxjnl-2016-208524

15. Brostrom EB, Thunqvist P, Adenfelt G, Borling E, Katz-Salamon M. Obstructive lung disease in children with mild to severe BPD. Respir Med. (2010) 104:362-70. doi: 10.1016/j.rmed.2009.10.008

16. Kaplan E, Bar-Yishay E, Prais D, Klinger G, Mei-Zahav M, Mussaffi H, et al. Encouraging pulmonary outcome for surviving, neurologically intact, extremely premature infants in the postsurfactant era. Chest. (2012) 142:72533. doi: 10.1378/chest.11-1562

17. Kitchen WH, Olinsky A, Doyle LW, Ford GW, Murton LJ, Slonim L, et al. Respiratory health and lung function in 8-year-old children of very low birth weight: a cohort study. Pediatrics. (1992) 89:1151-8.

18. Winck AD, Heinzmann-Filho JP, Schumann D, Zatti H, Mattiello R, Jones $\mathrm{MH}$, et al. Growth, lung function, and physical activity in schoolchildren who were very-low-birth-weight preterm infants. J Bras Pneumol. (2016) 42:254-60. doi: 10.1590/s1806-37562015000000159

19. Fawke J, Lum S, Kirkby J, Hennessy E, Marlow N, Rowell V, et al. Lung function and respiratory symptoms at 11 years in children born extremely preterm: the EPICure study. Am J Respir Crit Care Med. (2010) 182:23745. doi: 10.1164/rccm.200912-1806OC

20. Mohlkert LA, Sjoberg G, Rydberg A, Pegelow Halvorsen C, Tufvesson E, Hallberg J, et al. Lung function and pulmonary vascular resistance are not associated in 6-year-old children born extremely preterm. Acta Paediatr. (2019) 109:746-53. doi: 10.1111/apa.15030

21. Vrijlandt EJ, Boezen HM, Gerritsen J, Stremmelaar EF, Duiverman EJ. Respiratory health in prematurely born preschool children with and without bronchopulmonary dysplasia. J Pediatr. (2007) 150:25661. doi: 10.1016/j.jpeds.2006.12.007

22. Jobe AH, Bancalari E. Bronchopulmonary dysplasia. Am J Respir Crit Care Med. (2001) 163:1723-9. doi: 10.1164/ajrccm.163.7.2011060

23. Miller MR, Crapo R, Hankinson J, Brusasco V, Burgos F, Casaburi R, et al. General considerations for lung function testing. Eur Respir J. (2005) 26:15361. doi: 10.1183/09031936.05.00034505

24. Quanjer PH, Stanojevic S, Cole TJ, Baur X, Hall GL, Culver BH, et al. Multi-ethnic reference values for spirometry for the 3-95-yr age range: the global lung function 2012 equations. Eur Respir J. (2012) 40:132443. doi: $10.1183 / 09031936.00080312$

25. Asher MI, Keil U, Anderson HR, Beasley R, Crane J, Martinez $\mathrm{F}$, et al. International Study of Asthma and Allergies in Childhood (ISAAC): rationale and methods. Eur Respir J. (1995) 8:483-91. doi: 10.1183/09031936.95.08030483

26. Simpson SJ, Turkovic L, Wilson AC, Verheggen M, Logie KM, Pillow JJ, et al. Lung function trajectories throughout childhood in survivors of very preterm birth: a longitudinal cohort study. Lancet Child Adolesc Health. (2018) 2:350-9. doi: 10.1016/S2352-4642(18)30064-6

27. Hacking DF, Gibson AM, Robertson C, Doyle LW, Victorian G. Infant Collaborative Study, Respiratory function at age 8-9 after extremely low birthweight or preterm birth in Victoria in 1997. Pediatr Pulmonol. (2013) 48:449-55. doi: 10.1002/ppul.22619

28. den Dekker HT, Sonnenschein-van der Voort AMM, de Jongste JC, AnessiMaesano I, Arshad SH, Barros H, et al. Early growth characteristics and the risk of reduced lung function and asthma: a meta-analysis of 25,000 children. J Allergy Clin Immunol. (2016) 137:1026-35. doi: 10.1016/j.jaci.2015.08.050

29. Simpson SJ, Logie KM, O’Dea CA, Banton GL, Murray C, Wilson AC, et al. Altered lung structure and function in mid-childhood survivors of very preterm birth. Thorax. (2017) 72:702-11. doi: 10.1136/thoraxjnl-2016-208985

30. Lawlor DA, Ebrahim S, Davey Smith G. Association of birth weight with adult lung function: findings from the British Women's Heart and Health Study and a meta-analysis. Thorax. (2005) 60:851-8. doi: 10.1136/thx.2005.042408

31. Simpson SJ, Hall GL, Wilson AC. Lung function following very preterm birth in the era of 'new' bronchopulmonary dysplasia. Respirology. (2015) 20:535-40. doi: 10.1111/resp. 12503

32. Vom Hove M, Prenzel F, Uhlig HH, Robel-Tillig E. Pulmonary outcome in former preterm, very low birth weight children with bronchopulmonary dysplasia: a case-control follow-up at school age. J Pediatr. (2014) 164:40-5 e4. doi: 10.1016/j.jpeds.2013.07.045

33. Sanchez-Solis M, Garcia-Marcos L, Bosch-Gimenez V, Perez-Fernandez V, Pastor-Vivero MD, Mondejar-Lopez P. Lung function among infants born preterm, with or without bronchopulmonary dysplasia. Pediatr Pulmonol. (2012) 47:674-81. doi: 10.1002/ppul.21609

34. Um-Bergstrom P, Hallberg J, Thunqvist P, Berggren-Brostrom E, Anderson $M$, Adenfelt $G$, et al. Lung function development after preterm birth in relation to severity of Bronchopulmonary dysplasia. BMC Pulm Med. (2017) 17:97. doi: 10.1186/s12890-017-0441-3

35. Hirata K, Nishihara M, Shiraishi J, Hirano S, Matsunami K, Sumi K, et al. Perinatal factors associated with long-term respiratory sequelae in extremely low birthweight infants. Arch Dis Child Fetal Neonatal Ed. (2015) 100:F3149. doi: 10.1136/archdischild-2014-306931

36. Doyle LW, Carse E, Adams AM, Ranganathan S, Opie G, Cheong JLY, et al. Infant collaborative study, ventilation in extremely preterm infants and respiratory function at 8 years. N Engl J Med. (2017) 377:32937. doi: 10.1056/NEJMoa 1700827

37. Sanchez-Solis M, Garcia-Marcos PW, Aguera-Arenas J, MondejarLopez P, Garcia-Marcos L. Impact of early caffeine therapy in preterm newborns on infant lung function. Pediatr Pulmonol. (2020) 55:102-7. doi: $10.1002 /$ ppul.24540 
38. Toftlund LH, Agertoft L, Halken S, Zachariassen G. Improved lung function at age 6 in children born very preterm and fed extra protein postdischarge. Pediatr Allergy Immunol. (2019) 30:47-54. doi: 10.1111/pai. 12981

39. Isayama T, Lee SK, Yang J, Lee D, Daspal S, Dunn M, et al. Revisiting the definition of bronchopulmonary dysplasia: effect of changing panoply of respiratory support for preterm neonates. JAMA Pediatr. (2017) 171:2719. doi: 10.1001/jamapediatrics.2016.4141

40. Doyle LW, Cheung MM, Ford GW, Olinsky A, Davis NM, Callanan C. Birth weight $<1,501 \mathrm{~g}$ and respiratory health at age 14. Arch Dis Child. (2001) 84:40-4. doi: 10.1136/adc.84.1.40

41. Jung E, Lee BS. Late-onset sepsis as a risk factor for bronchopulmonary dysplasia in extremely low birth weight infants: a nationwide cohort study. Sci Rep. (2019) 9:15448. doi: 10.1038/s41598-01951617-8
42. Balany J, Bhandari V. Understanding the impact of infection, inflammation, and their persistence in the pathogenesis of bronchopulmonary dysplasia. Front Med. (2015) 2:90. doi: 10.3389/fmed.2015.00090

Conflict of Interest: The authors declare that the research was conducted in the absence of any commercial or financial relationships that could be construed as a potential conflict of interest.

Copyright (C) 2020 Chang, Chang, Chi, Hsu, Lin, Jim and Peng. This is an open-access article distributed under the terms of the Creative Commons Attribution License (CC $B Y)$. The use, distribution or reproduction in other forums is permitted, provided the original author(s) and the copyright owner(s) are credited and that the original publication in this journal is cited, in accordance with accepted academic practice. No use, distribution or reproduction is permitted which does not comply with these terms. 